\title{
PERANCANGAN DAN DESAIN SISTEM CUSTOMER PT. TELEKOMUNIKASI INDONESIA (TELKOM) KANDATEL UNGARAN
}

\author{
Moch. Subchan Mauludin \\ Program Studi Teknik Informatika Fakultas Teknik \\ Universitas Wahid Hasyim \\ Email: aan.subhan18@gmail.com \\ Misbakhudin \\ Program Studi Teknik Informatika Fakultas Teknik \\ Universitas Wahid Hasyim
}

\begin{abstract}
ABSTRAK
Era globalisasi dan perdagangan bebas sekarang ini kebutuhan seseorang akan informasi semakin meningkat. PT Telekomunikasi Indonesia sebagai salah satu badan usaha yang bergerak di bidang jasa komunikasi keberadaanya benar-benar dibutuhkan masyarakat dalam hal pemenuhan kebutuhan informasi dan komunikasi. Pada saat ini PT Telekomunikasi Indonesia (TELKOM) kandatel Ungaran masih menggunakan sistem administrasi manual sehingga customer service mengalami kesulitan saat pencarian data, sehingga perlu dibuat perancangan sistem customer agar lebih praktis dan efisien dalam pencarian data. Sistem ini menggunakan metode SDLC (System Development Life Cycle) sehingga di hasilkan sebuah perancngan sistem informasi yang akurat, tepat, dan relevan di PT TELKOM kandatel Ungaran.
\end{abstract}

Kata kunci: administrasi, customerservice, SDLC, sistem.

\section{ABSTRACT}

Era of globalization and free trade seseorag need for information is increasing. PT Telekomunikasi Indonesia as one business entity engaged in the field of communication services existence truly needed by society in terms of meeting the needs of information and communication. At the moment PT Telekomunikasi Indonesia (TELKOM) Kandatel Ungaran still use manual administration system so that customer service experience difficulty collecting data, so it needs to be made the design of a customer's system to be more practical and efficient in the search data. This system uses the method of SDLC (System Development Life Cycle) that produced a system perancngan information is accurate, precise, and relevant in PT TELKOM Kandatel Ungaran.

Keywords: administration, customerservice, SDLC, systems.

\section{PENDAHULUAN}

Di era globalisasi dan perdagangan bebas saat ini kebutuhan seorang akan informasi dan komunikasi semakin meningkat, PT. Telkom Indonesia sebagai salah satu badan usaha yang bergerak dalam bidang jasa komunikasi keberadaanya benar-benar sangat dibutuhkan oleh masyarakat dalam hal pemenuhan kebutuhan akan informasi dan komunikasi.

Pada saat ini PT. Telkom dituntut untuk meningkatkan kualitas pelayanan akan sarana dan pasarana telekomunikasi yang diperlukan oleh masyarakat khusus nya konsumen atau pelanggang jasa Telkom sering dengan kemajuan ilmu pengetahuan dan teknologi informasi dan komunikasi pada saat ini telah melahirkan suatu persaingan yang sangat kompetitif antar negara. Hal ini tentu saja menuntut kemampuan manajemen pelayanan untuk memberikan system informasi yang cepat, tepat dan akurat kepada konsumen atau pelanggan.

Sistem informasi pelayanan yang dimiliki oleh PT. Telkom saat ini adalah suatu sistem yang bisa di katakan masih menggunakan sistem manual terkusus dalam pendaftaran atau pemasanaan sehingga belum efisien. Sebagai salah satu sarana komunakasi yang banyak dipergunakan maka PT. Telkom diharapkan mampu untuk selalu konsisten pada perananya, terutama kuantitas dan kualitas pelayanan dalam upaya memuaskan kebutuhan dan keinginan konsumen atau pelanggan 


\section{LANDASAN TEORI}

\subsection{Konsep Dasar Sistem}

Konsep dasar tentang sistem pertama kali ditemukan oleh Bertalanffy dan Ashby 1940. Konsep ini pada awalnya dikaji berdasarkan filosofi ilmu pengetahuan yang meliputi ilmu tehnik, fisika, biologi, teori organisasi, manajemen, dan ekonomi. Saat ini kajian tersebut juga sebagai teori sistem.

Sistem adalah kumpulan dari komponen-komponen peralatan model requirements, funtion dan interface. Sistem padaa dasarnya adalah sekelompok unsur yang erat hubunganya satukesatuan dalam usaha mencapai suatu tujuan.

Dari beberapa definisi mengenai sistem, dapat diambil kesimpuan bahwa sistem adalah suatu kesatuan prosedur atau elemen yang saling berintegrasi atau bekerja sama (sinergi) satu dengan yang lainya dalam proses mengolah masukan menjadi keluaran yang di inginkan atau sesuai sasaran untuk mencapai suatu tujuan.

\subsection{Konsep Dasar Informasi}

Informasi merupakan data yang telah diproses sehingga mempunyai arti tertentu bagi penerimanya. Sumber dari informasi adalah data, sedangkan data itu sendiri adalah kenyataan yang menggambarkan suatu kejadian, sedangkan kejadian itu merupakan suatu pristiwa yang terjadi pada waktu tertentu dalam hal ini informasi dan data saling berkaitan. Informasi diartikan sebagai data yang di olah menjadi bentuk yang lebuh berguna dan lebih berarti bagi yang menerimanya [1]. Informasi sebagai data yang telah diproses sedemikian rupa sehingga mengingatkan pengetahuan seseorang yang menggunakan data tersebut. Dari definisi tersebut dapat disampaikan bahwa informasi sebagai pengolahan data yang menghasilkan bentuk yang lebih berguna bagi penerimanya dan bermanfaat untuk pengambilan keputusan bisnis.

Nilai informasi dikatakan sempurna apabila perbedaan antara kebijakan optimal tanpa informasi yang sempruna dapat di nyatakan dengan jelas. Suatu informasi dapat di katakan bernilai berdasarkan sifatnya, antara lain [2] :

1) Kemudahan dalam memperoleh informasi mempunyai nilai yang lebih sempurna apabila dapat diperoleh secara mudah. Informasi dapat diperoleh dengan mudah jika sistem dilengkapi oleh basis data dan bagian pengolahan yang mampu mengolah data dengan baik untuk memenuhi segala kebutuhan informasi secara mudah.

2) Sifat luas dan kelengkapanya Informasi mempunyai nilai yang lebih sempurna apabila mempunyai lingkup/cakupan yang luas dan lengkap. Sifat luas dan lengkap tersebut memperlukan dukungan basis data yang cukup lengkap dan terstruktur dengan baik.

3) Ketelitian Informasi mempunyai nilai yang lebih sempurna apabila mempunyai nilai ketelitian yang tinggi/akurat. Hal ini memperlukan adanya proses validasi setiap data yang diinputkan ke dalam basis data.

4) Kecocokan dengan pengguna Informasi mempunyai nilai yang lebih sempurna apabila sesuai dengan kebutuhan penggunanya.

5) Kecepatan waktu Informasi mempunyai nilai yang lebih sempurna apabila dapat diteima oleh pengguna pada saat yang tepat. Informasi yang mampu mengolah data secara tepat.

6) Kejelasan Informasi yang jelas akan meningkatkan kesempurnaan nilai informasi. Kejelasan informasi dipengaruhi oleh bentuk dan format informasi.

7) Fleksibilitas Nilai informasi semakin sempurna apabila memiliki fleksibilitas tinggi. Fleksibilitas informasi diperlukan oleh para manajer/pimpinan pada saat pengambilan keputusan.

8) Dapat dibuktikan Informasi semakin sempurna apabila informasi tersebut dapat dibuktikan kebenaranya. Kebenaran informasi bergantung pada validitas data sumber yang diolah.

9) Tidak ada prasangka Informasi mempunyai nilai yang lebih sempurna apabila informasi tersebut tidak menimbulkan prasangka dan keraaguan adanya kesalahan. Kesalahan tersebut dapat terjadi akibat kesalahan data atau prosedur pengolahan.

10)Dapat diukur Informasi untuk pengambilan keputusan seharusnya dapat di ukur agar dapat mencapai nilai yang sempurna. Pengukuran informasi umumnya di maksudkan untuk mengukur dan melacak kembali validitas dan sumber yang digunakan.

Untuk memperoleh informasi yang bermanfaat bagi penerimnya, perlu di jelaskan bagai mana siklus yang terjadi atau dibutuhkan dalam menghasilkan informasi [3]. 


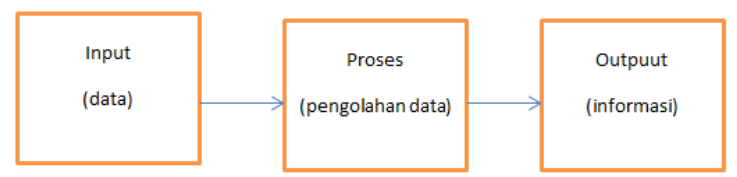

Gambar 1. Siklus Informasi

\subsection{Konsep Dasar Sistem Informasi}

Sistem informasi adalah suatu kombinasi antar prosedur kerja, informasi, orang dan teknologi informasi yang diorganisasikan untuk mencapai tujuan dalam sebuah organisasi. [4]. Sedangkan definisi sistem informasi dalam buku Informatioan Technology for Management Making Connection For Strategies Adventages adalah sistem informasi sebagai sistem yang mengumpilkan, memproses, menyimpan, menganalisis dan menyebarkan informasi untuk tujuan yang spesifik [5].

Sistem Informasi adalah suatu sistem buatan manusia yang secara umum terdiri atas sekumpulan komponen berbasis komputer dan manual yang di buat untuk menghimpun, menyimpan, dan mengelola data serta menyediakan informasi keluaran kepada para pemakai [6]. Dari definisi-definisi sebelumnya maka sistem informasi merupakan kombinasi hardware, software, brainware, jaringan komunikasi yang diorganisasikan untuk mencapai tujuan spesifik dan dapat digunakan untuk membantu pengambilan keputusan yang tepat dalam suatu organisasi.

\subsubsection{Komponen Sistem Informasi}

Komponen dasar sistem informasi dapat di kelompokan sebagai berikut [7]

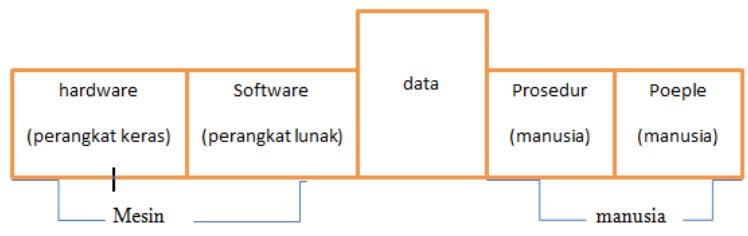

Gambar 2. Lima Komponen Sistem Informasi

1) Hardware dan software yang berfungsi sebagai mesin.

2) People dan procedure yang merupakan manusia dan tatacara menggunakan mesin.

3) Data merupakan jembatan penghubung anatara manusia dan mesin agar terjadi suatu proses pengolah data.

\subsubsection{Kegiatan Sistem Informasi}

Sistem informasi mengumpulkan, memproses, menyajikan, menganalisis, dan mendistribusikan informasi untuk tujuan tertentu. Seperti sistem lain, kegiatan sistem informasi meliputi [7].

1) Input Menggambarkan suatu kegiatan untuk menyediakan data untuk diproses.

2) Proses

Menggambarkan bagaimana suatu data diproses untuk menghasilkan suatu informas yang bernilai tambah.

3) Output

Suatu kegiatan untuk menghasilkan laporan dari proses diatas tersebut.

4) Penyimpanan

Suatu kegiatan untuk memelihata dan menyimpan data.

5) Control

Suatu aktivitas untuk menjamin bahwa sistem informasi tersebut berjalan sesuai dengan yang di harapkan

\section{METODOLOGI}

\subsection{Metode SDLC}


System Development Life Cycle (SDLC) atau siklus hidup pengembngan sistem adalah metode penegmbangan sistem tradisional yang di gunakan sebagaian besar organisasi saat ini. SDLC adalah kerangka kerja (framework) yang tersetruktur yang berisi proses proses sekuensial dimana sistem informasi di kembngkan [5].

\subsection{Tahapan SDLC}

Setiap pengembang mempunyai strategi yang berlainan, namun demikian pada dasarnya siklus hidup pengembangan sistem informasi terdapat 5 (lima) tahapan, yaitu :

1) Perencanaan Sistem (Systems Planning)

2) Analisis Sistem (System Analysis)

3) Perancangan Sistem (System Design)

4) Implementasi Sistem (System Implementation)

5) Penggunaan sistem (System Utilization)

\section{HASIL}

\subsection{Desain Sistem}

\subsubsection{Flowchart}

Flowchart adalah aliran proses, pendaftaran di telkom kandatel ungaran dengan alur admin login untuk masuk ke halam utama, kemudian admin memasukan biodata pendaftar atau pelanggan, langkah selanjutnya admin memeriksa kelengkapan berkas pendaftaran seperti fotocopy ktp, denah lokasi, dan mengisi formulir pendaftaran, bila berkas komplit maka akan disetujui dan langsung terdaftar sebagai pelanggan.

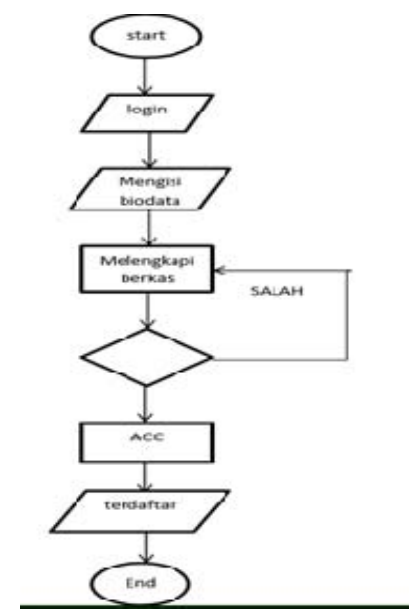

Gambar 3. Flowchart Sistem Pendaftaran

\subsubsection{Use Case}
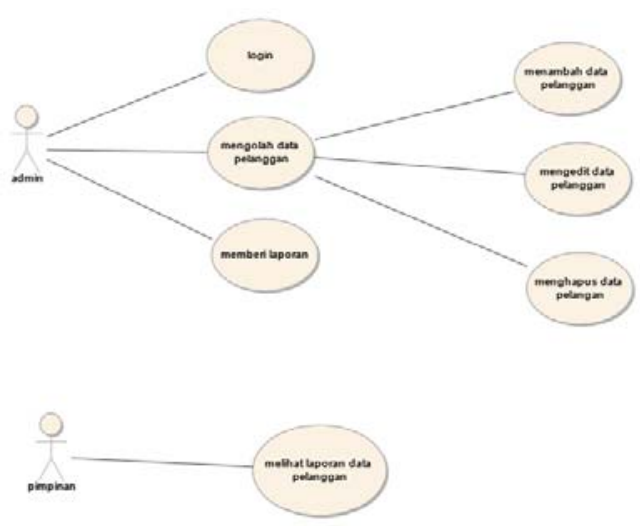

Gambar 4. Use Case 
Diagram Use Case pada gambar 4 diatas menggambarkan interaksi antara use case dan aktor seperti admin melakukan login, mengolah data, seperti menambah data pelanggan, mengedit data pelanggan, menghapus data pelanggan dan memberi laporan kepada pimpinan, sedangkan pimpinan hanya bisa melihat laporan data pelanggan.

Activity Diagram pada gambar 5 menggambarkan rangkaian aliran aktivitas atau memodelkan alur kerja dalam sebuah proses. Admin memasukan user dan password, sistem akan memvalidasi kebenaran data tersebut. Jika benar maka sistem akan melanjutkan ke tampilan utama, dalam halaman utama ada beberapa pilihan menu jika admin memilih salah satu menu sistem akan memprosesnya kemudian akan menampilkan halaman yang di pilih.

\subsubsection{Activity Diagram}

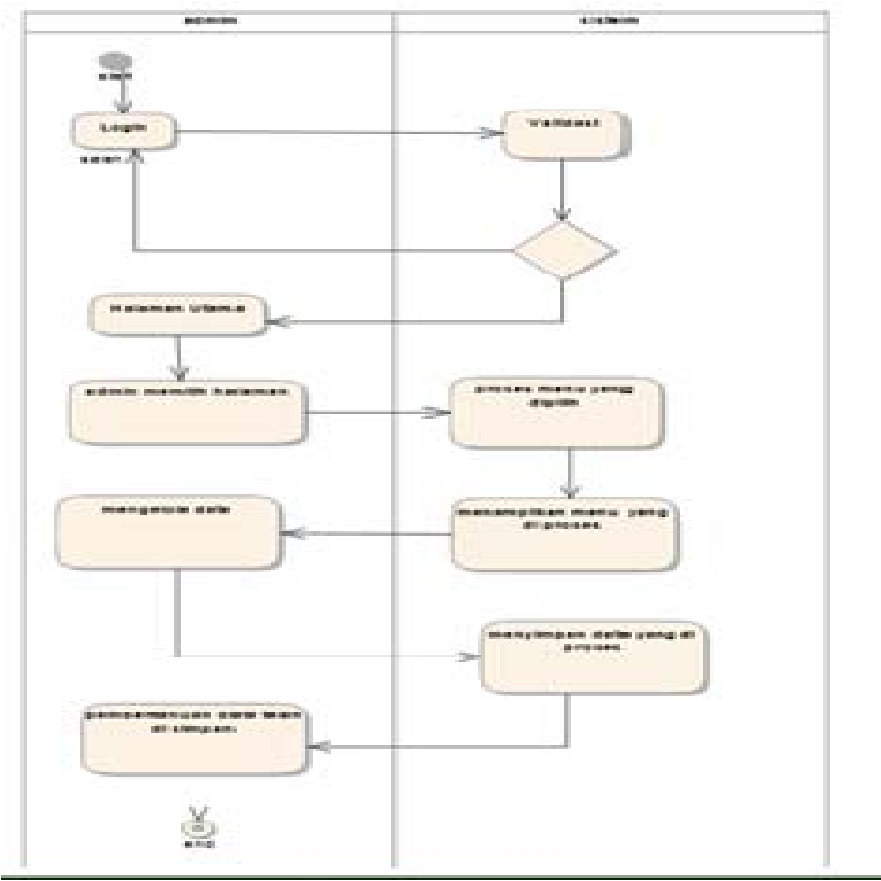

Gambar 5. Aktivity Diagram

\subsection{Desain Tampilan}

\subsubsection{Halaman Login}

\section{LOGIN USER PT TELKOM UNGARAN}

\section{LOGIN DI SINI}

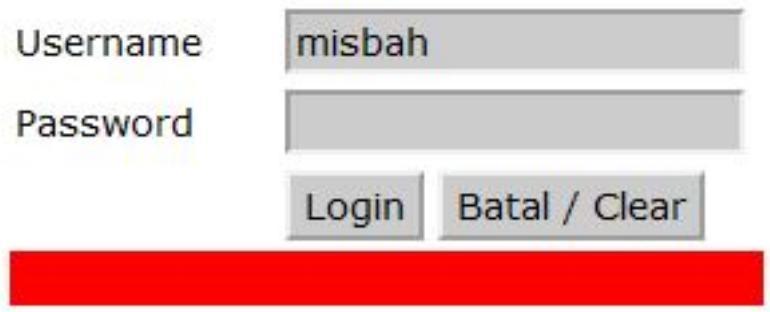

Gambar 6. Halaman Login 
Pada halam login ini admin atau costumer service harus mengisi atau memasukan alamat atau akun yang telah di tetapkan oleh perusahaan untuk masuk ke halaman utama. Login sendiri untuk memastikan supaya siapapun tidak bisa masuk ke web untuk menjaga kerahasiaan perusahaan atau data itu sendiri.

\subsubsection{Halaman Utama}

SELAMAT DATANG DI SISTEM INFORMASI PT TELKOM UNGARAN

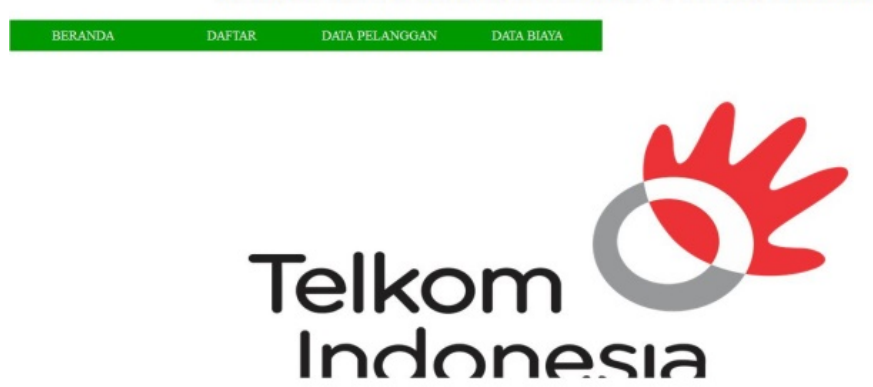

\section{Gambar 7. Halaman Utama}

Halaman utama berisikan menu atau pilihan yang ingin di kunjungi. Pada halaman utama ini terdapat menu beranda, daftar, data pelanggan dan data biaya.

\subsubsection{Halaman Daftar}

SELAMAT DATANG DI SISTEM INFORMASI PT TELKOM UNGARAN

BERANDA DAFTAR DATA PEL.ANGGAN DATA BLAYA

\section{FORMULIR PENDAFTARAN}
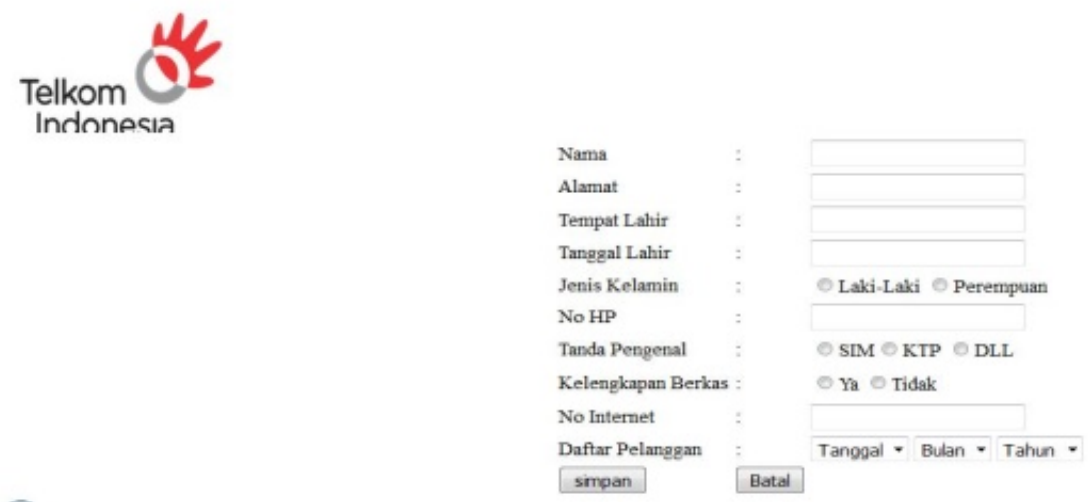

Gambar 8. Halaman Daftar

Di menu ini berisikan form pendaftaran sehingga data calon pelanggan bisa langsung diinputkan ke form yang tersedia agar bisa langsung tersimpan dan masuk ke data. 


\subsubsection{Halaman Pelanggan}

\section{SELAMAT DATANG DI SISTEM INFORMASI PT TELKOM UNGARAN}

\section{BERANDA DAFTAR DATA PELANGGAN DATA BIAYA}

Cari Berdasarkan Nama Pelanggan •

Data Pelanggan

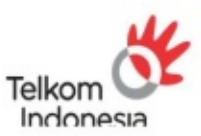

\begin{tabular}{|l|l|l|l|}
\hline No & Nama & Alamat & No Intemet \\
\hline 1 & Misbah & Ungaran & 08988 \\
\hline 2 & & & \\
\hline 3 & & & \\
\hline
\end{tabular}

Gambar 9. Halaman Pelanggan

Halaman pelanggan ini berisikan semua informasi mengenai data pelanggan.

\subsubsection{Halaman Biaya}

SELAMAT DATANG DI SISTEM INFORMASI PT TELKOM UNGARAN
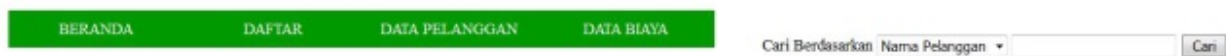

\section{DATA BIAYA}
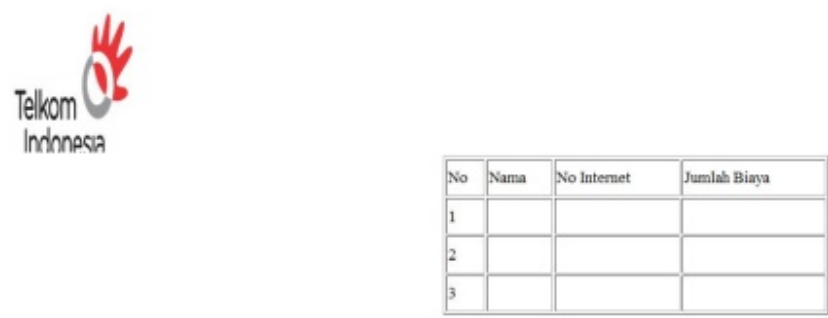

Gambar 10. Halaman Data Biaya

Halaman data biaya ini berisikan nama-nama pelangan dan jumlah tarif yang harus di bayarkan sehingga dengan mudah perusahaan melihat laporan.

\section{KESIMPULAN}

Perancangan sistem informasi data pelanggan ini pengembangan dari sistem yang sedang berjalan. Berdasarkan dari latar belakang dapat ditarik kesimpulan sistem informasi di PT TELKOM kandatel Ungaran masih berjalan manual, sehingga mengakibatkan layanan atau laporan kepada pimpinan kurang maksimal.

1) Perancangan sistem informasi ini bertujuan untuk mempermudah perusahaan menyajikan informasi tentang data pelanggan.

2) Sistem informasi ini dapat memberikan informasi dengan cepat, akurat dan relevan. Sistem di rancang dengan desain yang sederhana sehingga pengguna dari sistem ini bisa menjalankan dengan baik. 


\section{DAFTAR PUSTAKA}

[1] Hartono J. 2000. Pengenalan Komputer. Yogyakarta: Andi.

[2] Sutanta E. 2003. Sistem Informasi Manajemen, Edisi 1, Cetakan I. Penerbit Graha Ilmu, Yogyakarta.

[3] Jogiyanto 2005. Analisis dan Desain Sistem Informasi. Andi. Yogyakarta.

[4] Alter S. 2002. Information System: Foundation of E-Business. Prentice Hall.

[5] Turban E, Rainer JRK, Porter RE. 2004. Information to Information Technology. John wiley \& sons, USA.

[6] Kadir A. 2003. Pengenalan Teknologi Informasi. Penerbit: Andi, Yogyakarta.

[7] Ladjamudin AB. 2005. Analisis dan Desain Sistem Informasi. Graha Ilmu: Yogyakarta. 